\title{
E-Maturity: entrelaçando gestão, tecnologia e pedagogia
}

\author{
Herik Zednik Rodrigues ${ }^{1}$, Liane M. R. Tarouco ${ }^{1}$, Luis R. Klering ${ }^{2}$ \\ ${ }^{1}$ Programa de Pós-graduação em Informática na Educação - Universidade Federal \\ do Rio Grande do Sul (UFRGS) \\ ${ }^{2}$ Faculdade de Administração -Universidade Federal do Rio Grande do Sul \\ (UFRGS) \\ herik.zednik@ufrgs.br, liane@penta.ufrgs.br, rsf2708@via-rs.net
}

\begin{abstract}
This paper presents a theoretical approach that seeks to understand and conceptualize the term e-maturity (electronics maturity), whose study is part of doctoral research named E-Maturity: technology management based in improving educational performance, developed by the Program of PhD in Technology in Education (PPGIE name in Portuguese) at Federal University of Rio Grande do Sul. To justify the term (e-maturity) used in this research, we seek for the Theory of Maturity-Immaturity of Chris Argyris (1969) and have been analysed the Model Maturity of Capability of Software based in Software Engineering.
\end{abstract}

Keywords: e-maturity. Management. Technology. Pedagogy

Resumo. Este artigo apresenta uma abordagem teórica que busca compreender e conceituar o termo e-maturity (maturidade eletrônica), cujo estudo se justifica por ser foco da pesquisa de doutorado intitulada Ematurity: gestão da tecnologia em função da melhoria do desempenho educacional, desenvolvida no Programa de Pós-Graduação em Informática na Educação (PPGIE), da Universidade Federal do Rio Grande do Sul. Para fundamentar o termo (e-maturity) utilizado na pesquisa, retomamos a Teoria da Maturidade-imaturidade, de Chris Argyris (1969), e, buscamos na Engenharia de Software, o Modelo de Maturidade de Capacidade de Software- CMM.

Palavras-chaves: maturidade eletrônica. Gestão. Tecnologia. Pedagogia.

\section{Introdução}

Diferentes setores da sociedade sentem o forte impacto das mudanças trazidas pelas novas Tecnologias de Informação e Comunicação (TICs). Elas não só trouxeram agilidade às formas de se comunicar, como mudaram hábitos e posturas nas áreas econômica, social, política, cultural e de entretenimento. As mudanças são tão fortes que muitos órgãos como a Organização das Nações Unidas (ONU), Organização para a Cooperação e Desenvolvimento Econômico (OCDE), Banco Mundial, entre outros se dedicaram a pesquisar e analisar essa revolução.

Essas mudanças também estão presentes no contexto educacional. No entanto, muitos educadores denunciam um descompasso entre escola e desenvolvimento tecnológico. Nesse sentido, cabe uma reflexão sobre qual o papel da gestão frente a essas mudanças? Sabemos que a Tecnologia, Informação e Comunicação é uma necessidade inerente ao homem e sempre esteve presente em todas as escolas desde 
tempos remotos sob as mais diversas formas e pode transformar-se em um poderoso diferencial educativo, desde que sua utilização esteja alinhada a uma gestão didática eficiente, com uso de tecnologia atualizada e uma prática pedagógica adequada, otimizando seu potencial colaborativo, definindo coletivamente métodos e estratégias, estabelecendo indicadores e currículos que sejam capazes de redimensionar a escola para que esta ajude no desenvolvimento dessa nova geração.

Gerenciar a Tecnologia da Informação e Comunicação (TIC) no contexto escolar não é só manter atualizado um conjunto de equipamentos que exigem constantes melhorias e manutenções sem fim ou promover formações aligeiradas para seu uso. Significa, sim, escolher e avaliar as soluções tecnológicas (envolvendo hardware e software) que efetivamente colaborem para melhorias nos resultados educacionais, aplicadas dentro de um contexto didático metodológico. Que realmente (e comprovadamente) reduzam os custos operacionais, que ajudem ao processo de ensino e aprendizagem, que favoreçam o planejamento estratégico, que melhorem as condições de trabalho dos professores e funcionários; enfim, que aumentem as margens de eficiência e eficácia das escolas. Nesse sentido, o conjunto de habilidades exigidas dos gestores escolares está cada vez maior e abrange várias áreas do conhecimento. Essas novas habilidades trazem à tona a necessidade de uma maturidade eletrônica ( $e$ maturity), cujo conceito é o foco desse estudo.

\section{Contexto}

O Brasil apresentou, em 2006, no PISA ${ }^{1}$ (Programme for International Student Assesment $)^{2}$, entre 28 países participantes, o seguinte resultado: $27^{\circ}$ em Matemática e $25^{\circ}$ em Português. Em 2007, alcançou, entre os 57 países participantes, a $54^{\circ}$ colocação em Matemática e a $52^{\circ}$ colocação em Português. Em 2009, ficou na $53^{a}$ posição, entre 65 países envolvidos na avaliação.

Países da União Europeia são recordistas em investimentos em tecnologias. A Itália, por exemplo, lidera na implantação de telemóveis de $3^{\text {a }}$ geração e fibra ótica; o Reino Unido lidera no número de famílias com TV Digital; a Dinamarca, Finlândia, Suécia e Reino Unido ultrapassam inclusive EUA e Japão em taxas de penetração da banda larga; a Finlândia, Dinamarca e Suécia possuem 100\% das escolas com acesso a banda larga e investem em conteúdos educacionais ${ }^{3}$.

O resultado de todo esse investimento dos três países (Finlândia, Dinamarca e Suécia) aparece na conquista, por eles, dos melhores resultados no PISA. No último exame (de 2009), países como China e Coreia obtiveram $1^{\mathrm{a}}$. e $2^{\mathrm{a}}$. colocação respectivamente.

[...] em termos comparativos, o índice de difusão brasileiro ainda é bastante baixo $(4,3 \%)$, sendo muito inferior ao verificado nos países desenvolvidos e também inferior ao de vários países em desenvolvimento, como Turquia $(6,2 \%)$, Argentina (6\%) e China (5\%). Atualmente, os países da OCDE são os líderes mundiais em difusão da banda larga (média de 15 assinantes por 100 habitantes). Em 2007, cinco países da organização possuíam ao menos 30 assinantes por 100 habitantes (Dinamarca, Holanda, Suíça, Coreia e Suécia) (Rauen e Hiratuka, 2010, p. 509).

Estariam esses resultados ligados à falta de maturidade eletrônica das organizações escolares? Ou estes países, por possuírem uma educação de qualidade (e consequentemente uma população com mais acesso aos bens culturais e alunos mais instruídos), necessariamente investem mais em tecnologia, inclusive na educação? Não podemos afirmar com certeza, afinal muitas seriam as variáveis para análise dos dados acima. 
O que podemos aprender com esses resultados? Este cenário permite, ao Brasil, analisar os resultados e investimentos feitos em outros países, de forma que o ajude a encurtar distâncias, transpor barreiras e saltar etapas através do intercâmbio de experiências. "Países mal avaliados, como o Brasil, devem aproveitar para realizarem "leapfrog": saltar estágios, indo para estágios mais avançados, através do trampolim da tecnologia, sem precisar passar pelos mesmos estágios que os países hoje desenvolvidos passaram" (Negroponte, apud Chaves, 2010).

É essencial perceber que o século XXI exige uma educação diferente da que tivemos na época do império. O desafio é colocar a escola brasileira no século XXI com o perfil adequado; caso contrário, continuaremos reforçando o enorme descompasso entre a escola e a atual geração. Nesse sentido, Libâneo (2000, p. 25) diz: "Somos professores do século XX, trabalhando conteúdos do século XIX e ensinando a alunos do século XXI".

A internet revolucionou as formas de pensar, interagir, trabalhar e relacionar pessoas, dando origem a uma geração multifuncional, com amplo acesso a equipamentos multimídia (junção das diversas mídias). A multimídia se torna interativa quando as ações dos alunos afetam a forma e conteúdo da apresentação.

Os jovens falam ao telefone, jogam kinect ${ }^{4}$, trocam mensagens de texto, baixam músicas, fazem envio (upload) de vídeos para o You Tube e imagens no Flickr ${ }^{5}$, assistem a um filme em uma tela de duas polegadas ou numa TV 3D de 50", criam blogs ${ }^{6}$ e navegam pelo Orkut, Twitter, Facebook ${ }^{7}$, tudo ao mesmo tempo. Podemos afirmar que a internet mudou hábitos, padrões de consumo, de relacionamentos e também de aprender.

Segundo Chaves (2010), o nativo digital possui as seguintes características: "lida extremamente bem com a tecnologia; faz múltiplas coisas ao mesmo tempo; tem iniciativa, é empreendedor; toma riscos; aprende fazendo (Hands on); aprende no tempo certo (Just in Time); aprende apenas o suficiente (Just Enough); tem pouca tolerância com coisas chatas ou que não lhe interessam”.

Como deve ser a escola em face dessas novas realidades que se impõem pelo avanço da tecnologia? O desafio é quebrar o grande paradigma de ela ser simplesmente uma mera instituição responsável pela transmissão de informações, e transformar-se num lugar de análises críticas, de produção da informação, que provoque o pensar, o criar, onde o conhecimento possibilite a atribuição de significado à informação. Nessa escola, os alunos devem aprender a aprender, a buscar o conhecimento em todos os lugares, nas aulas, no livro didático, na $\mathrm{TV}$, no rádio, no jornal, nos vídeos, no computador, na internet, no celular etc.

A otimização dos recursos tecnológicos no contexto escolar imprime a ideia de um processo de maturidade eletrônica necessária ao novo perfil escolar para atender a essa geração que nasceu com o advento da internet e para quem essa ferramenta não tem mistério.

O cenário atual apresenta significativas mudanças e muitos investimentos e esforços para introduzir a tecnologia nos organismos educacionais têm sido feito nos últimos anos. Nessa perspectiva, o Brasil e o Ceará, apontado nesse estudo por ser foco de estudos posteriores, têm tomado diversas iniciativas nos últimos anos com a finalidade de estimular o uso didático da tecnologia nas escolas. Programas e projetos como: Telecentros, GESAC, Computador Para Todos e o ProUCA (Programa Um Computador por Aluno) são exemplos dessas iniciativas. No Ceará, além de projetos como Ilhas Digitais e e-jovem, o estado foi pioneiro na implantação do Cinturão Digital, que favorecerá o acesso a serviços digitais, tais como internet, videoconferência, TV Digital, telefonia celular e outras ferramentas indispensáveis para o desenvolvimento 
econômico, além da criação de polos investigadores e produtores de conteúdo, por Universidades e iniciativa privada. Mas toda essa tecnologia só refletirá positivamente na educação se forem bem utilizadas pedagogicamente e isso naturalmente exige um processo de e-maturity necessária às instituições de ensino.

Essas mudanças impõem a necessidade de repensar papéis, metodologias, currículos e, fundamentalmente, a gestão. Para que a escola desenvolva a e-maturity, é imprescindível que entenda o processo de ensino e aprendizagem, utilizando-se de recursos das modernas TICs, de forma a colocar a tecnologia a serviço de uma proposta pedagógica definida coletivamente na escola, com foco no aumento da aprovação qualitativa e diminuição da evasão e reprovação.

Grande parte dos gestores e professores não utiliza o potencial das tecnologias para melhorar seus resultados educacionais, embora tenhamos algumas escolas razoavelmente bem equipadas. Essa análise conduz à hipótese de que falta ainda maturidade na instituição pública para fazer uso das TICs no contexto educacional de forma a favorecer o processo de ensino aprendizagem, sendo que esta imaturidade tem início na insuficiente formação de professores, permeia a gestão e enfoca o currículo da forma ainda tradicional e linear.

\section{O que é e-maturity?}

Para compreender o termo e-maturity fomos buscar na literatura do campo da administração a luz teórica que consolidasse a definição no contexto educacional.

Inicialmente, faz-se necessário explanar sobre a ideia de maturidade (maturity), conceito que ficou amplamente conhecido através do Capability Maturity Model (CMM) ou Modelo de Maturidade de Capacidade de Software, mas que teve origem com a Teoria da Maturidade-Imaturidade, de Chris Argyris (1969).

A etimologia da palavra revela, conforme o dicionário eletrônico Aurélio Holanda (2004), que maturidade vem do latim maturitate, que tem o mesmo significado que madureza, estado do que está maduro, ou seja, plenamente desenvolvido; indivíduo prudente, ponderado; perfeição, excelência, primor; firmeza, precisão, exatidão; circunspecção, siso, prudência; equilíbrio.

\section{1 - Teoria da Maturidade-Imaturidade}

A Teoria da Maturidade-Imaturidade foi criada por Chris Argyris nos anos de 19601970, e deu base para vários autores formularem o conceito de maturidade pessoal ou organizacional. A teoria defende que a evolução do sujeito no exercício de suas atividades "depende das condições que a organização lhe oferece e que a organização cria papéis e situações que mantêm a imaturidade dos empregados visando a adaptá-los ao trabalho, o que frustra seu desenvolvimento e os impede de alcançar plena satisfação no trabalho" (Argyris, 1969 apud Martinez e Paraguay, 2003). Desta forma, a teoria propõe mudanças a serem incorporadas nas organizações que possibilitem o pleno desenvolvimento das pessoas no desempenho de suas funções.

Segundo Argyris (1968), em seu livro Personalidade e organização: o conflito entre o sistema e o indivíduo, a imaturidade se manifesta quando o indivíduo apresenta características de ser passivo, dependente, com postura de subordinado, entre outras características, e evolui para a maturidade, em que se manifestam características tais como: ser ativo, independente, com postura igualitária, com interesses mais profundos, comportamento mais complexo e consciência e controle. A evolução da imaturidade para a maturidade traz mudanças organizacionais e nela "está implícita a idéia do 
homem valorizado e identificado com os objetivos da organização, possibilitando, desta maneira, alto grau de satisfação no trabalho e maior produtividade" (Pérez-Ramos, 1980, p. 61 apud Martinez e Paraguay, 2003).

A trajetória que conduz o sujeito a avançar da imaturidade em direção à maturidade se revela num homem reflexivo, participativo e, por sua vez, mais desenvolvido, inovador e criativo. A Teoria da Maturidade-Imaturidade destaca o resultado da liderança madura, em relação ao comportamento dos subordinados.

Com base na psicologia do desenvolvimento, a Teoria de Argyris estuda o crescimento e o desenvolvimento comportamental dos sujeitos e faz uma análise desde a infância até a fase adulta. Nessa direção,

[...] defende a ideia de que há necessidade de mudanças de personalidade para que o indivíduo atinja, plenamente, a maturidade, mas que, para que isto possa acontecer naturalmente, é necessário que este indivíduo possa exercer plenamente as suas habilidades e responsabilidades no seu dia-a-dia (Nehme, 1998, p. 42).

Conforme o autor, as mudanças dos estágios de maturidade evoluem de forma contínua de acordo com a visão de gestão de cada organização. O quadro abaixo apresenta as sete mudanças que devem acontecer na personalidade do indivíduo, segundo Argyris, para que seja considerado um sujeito maduro, com o passar do tempo. As mudanças se apresentam num contínuo, onde a evolução da imaturidade até a maturidade representa a personalidade sadia, e se desenvolve nesse contínuo.

Quadro 1 - Continuum da imaturidade - maturidade de Argyris

\begin{tabular}{|c|c|}
\hline Comportamento imaturo, infantil & Comportamento maturo, adulto \\
\hline 1. Passivo & 1. Ativo \\
\hline 2. Dependente & 2. Independente \\
\hline 3. Comportamento de poucas formas & 3. $\quad$ Muitas formas \\
\hline 4. Interesses casuais e superficiais & 4. Mais intensos, profundos \\
\hline 5. $\quad$ Perspectiva de curto prazo & 5. $\quad$ Longo prazo \\
\hline 6. Posição subordinada & 6. Igual ou superior \\
\hline 7. Falta de consciência própria & 7. Controle pessoal \\
\hline
\end{tabular}

Fonte: Chris Argyris - Personality and Organization . New York, Harper Brothers, 1957, p. 50-

53 apud Klering, 1994, p. 44.

É necessário destacar que os comportamentos apresentados no quadro acima dependem do autoconceito que o indivíduo tem de si mesmo, do seu grau de adaptação e de ajustamento, e da forma como vê seu mundo particular. Desta forma, Argyris, centra no que ele se refere como o trabalhador maduro e contrasta as práticas de gestão encontradas em organizações tradicionais com as necessidades e capacidades da personalidade adulta.

Além disso, Argyris (1969) preocupou-se sobre como os gestores tratam as pessoas. Defende que se os gerentes tratarem seus empregados de forma positiva, seus funcionários serão mais produtivos. Acredita que os trabalhadores maduros querem responsabilidades adicionais, uma variedade de tarefas, bem como a capacidade de participar nas decisões. Caso contrário, ele acredita que o resultado será absenteísmo, apatia, e até mesmo alienação.

\subsection{CMM - A Maturity Framework}

Esse modelo foi originado para as empresas de software, mas exerceu forte influência em pesquisas na área da administração de empresas, especialmente as voltadas para 
projetos. $\mathrm{O}$ foco desse modelo $(\mathrm{CMM})$ se alicerça nos processos implementados, através da estrutura determinada no grau de maturidade, pois "retratam a evolução da empresa desde práticas imaturas de gerenciamento de projeto até práticas mais sólidas, e relacionam a infraestrutura necessária para dar suporte aos projetos em um determinado nível organizacional" (Bruno, 2008).

A maturidade de uma instituição está associada à organização das normas e dos processos necessários para sua efetivação, isto é, "por meio de políticas, padrões, cultura corporativa, práticas gerenciais, estruturas organizacionais" (Bruno, 2008) e, mais recentemente, da implementação da tecnologia. Nesse sentido, a busca por resultados exitosos exige que as organizações consigam realizar uma gestão pautada em estágios e metas cada vez mais avançados, voltados para o refinamento de práticas gerenciais que colaborem com o alcance de melhores resultados.

Nesse contexto, de acordo com o Project Management Institute -PMI (2003) o conceito maturity implica:

Que as capacidades de gerenciamento devem evoluir ao longo do tempo com o objetivo de produzir de forma sistemática e contínua resultados de sucesso no gerenciamento de projetos. Maturity pode ser entendida como desenvolvimento total ou em perfeitas condições e também demonstra uma compreensão e domínio ou fornece visibilidade de como o sucesso ocorre e quais as abordagens para correção e prevenção de problemas comuns.

Humphrey (1987), em seu artigo, Characterizing the Software Process: a Maturity Framework, ressalta que a estrutura deste modelo, CMM, oferece cinco níveis de maturidade, os quais possibilitam a identificação das principais melhorias necessárias em cada nível, e direciona uma ordem de prioridade para a execução, a partir dos resultados positivos alcançados em cada estágio, em que estes servem como alicerce para o próximo, consequentemente, impulsionam o desenvolvimento no processo em sua totalidade. Os níveis apontados por Humphrey (1987) são: inicial, repetível, definido, gerenciado e em otimização; cada nível de maturidade descreve as práticas necessárias para o crescimento progressivo. A figura abaixo representa os níveis, com seus diferentes componentes, essenciais para a melhoria da capacidade da empresa.

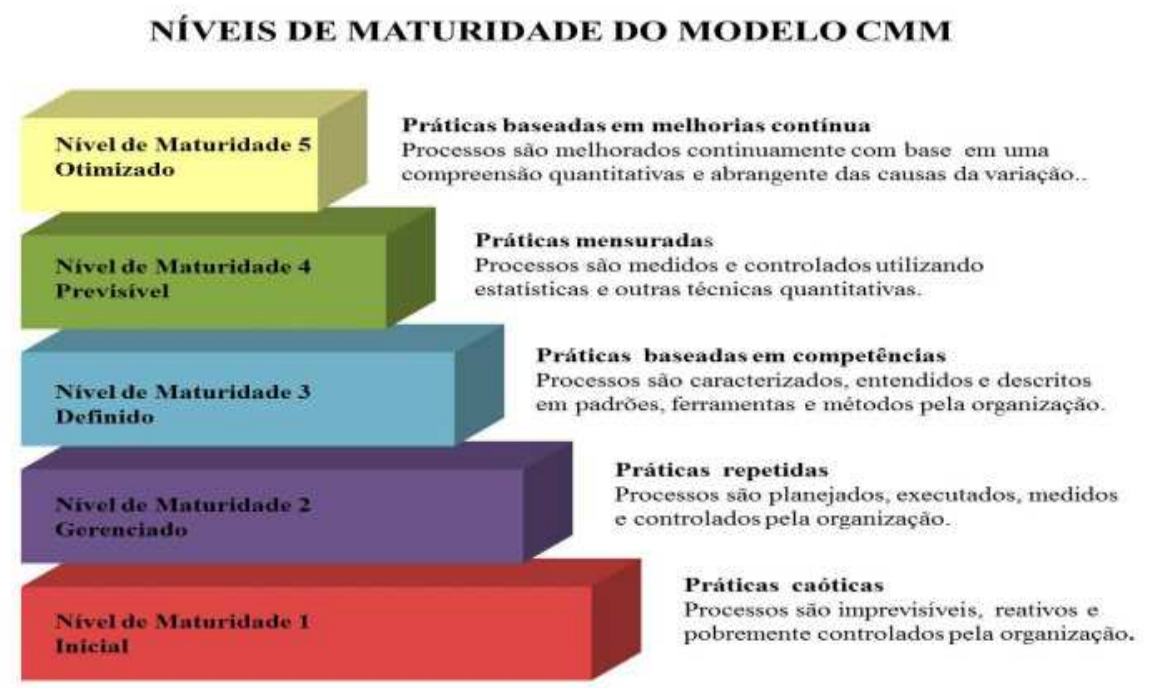

Figura 1 - Níveis de maturidade no CMM Fonte: Adaptado de Curtis, Hefley e Miller (2001) apud Bruno 2008 
7

A partir desse modelo, CMM, outros foram sendo implementados e utilizados pelas empresas como: Organizational Project Management Maturity Model (OPM3), People Capability Maturity Model (P-CMM), Knowledge Management Maturity Model (KMMM), Organizational Knowledge Assessment Methodology (OKA).

\subsection{E-maturity: conceito e compreensão}

O conceito geral de maturidade em educação baseia-se na ideia de amadurecimento como tendo crescido, desenvolvido em torno de um longo período de tempo, suficiente para saber promover mudanças positivas e planejar ações e estratégias inovadoras que contribuam para um melhor desempenho educacional.

Nesse sentido, considerando o contexto educacional, podemos compreender que não é suficiente introduzir a tecnologia nas escolas, faz-se necessário um contínuo e sistemático processo de amadurecimento da gestão tecnopedagógica, onde a escola evolua progressivamente sua capacidade de organização e de tomada de decisão estratégica, de forma a utilizar eficazmente a tecnologia para melhorar os índices educacionais. Em suma, gerir a mudança de cultura organizacional necessária para assegurar que o investimento em tecnologia seja aliado a práticas pedagógicas que conduzam à melhoria no processo de ensino e aprendizagem.

A presença constante da tecnologia no contexto educacional conduz à necessidade de repensar de que forma essa tecnologia foi introduzida e como a gestão pode fazer uso desses recursos para potencializar o trabalho pedagógico, desembocando na ideia de maturidade eletrônica (e-maturity).

Na educação, o termo passa a ser utilizado inicialmente pelo Relatório British Educational Communications and Technology Agency (Becta), uma agência governamental de aconselhamento sobre tecnologias de informação da Inglaterra, que conceitua e-maturity como "a capacidade de indivíduos e organizações em explorar o poder da tecnologia para melhorar os resultados educacionais" (2008).

Mas afinal, o que significa o termo e-maturity? Com base nos teóricos e estudos realizados, este trabalho conceitua e-maturity como a capacidade e potencialidade da organização escolar de tomar decisões estratégicas e utilizar de forma eficaz a tecnologia para melhorar os resultados educacionais.

Com base nesse conceito, destaca-se que a gestão escolar tem um grande desafio, pois a sociedade atual espera que estes sejam capazes de fazer uso criativo e inovador da tecnologia, superando medos e mitos, diminuindo o descompasso entre a escola e a tecnologia. Esse amadurecer no uso da tecnologia se reflete na prática pedagógica, mas exige também uma mudança de cultura que, por sua vez, "é uma variável que pode ser controlada, uma vez conhecida" (Nakaiama, 1997). Nesse sentido, a "cultura é gerenciável e pode ser modificada" (Mintzberg, 1998, Thévenet, 1986, Tomei, 1993, apud Nakaiama, 1997), mas demanda tempo.

Muitos estudos afirmam que o uso da tecnologia traz benefícios para a aprendizagem dos alunos quando dentro de uma proposta construcionista ${ }^{8}$. Os benefícios do uso adequado da tecnologia para estudantes incluem: maior concentração; maior receptividade à aprendizagem; aumento da confiança; melhor compreensão de conceitos (Becta 2005 e 2006). Esses benefícios permitem aos alunos participarem mais $\mathrm{e}$, portanto, interagirem mais.

Segundo dados do relatório Becta (2006), um terço dos professores entrevistados em todo o ensino relatou que o uso da tecnologia nos últimos três anos tinha melhorado o desempenho escolar (apenas $1 \%$ considera que usar a tecnologia piora a aprendizagem). Além disso, quase dois terços (64\%) dos professores entrevistados 
relataram que, usando e-learning, haviam desenvolvido a compreensão dos seus assuntos de forma mais eficaz.

Ainda segundo dados do relatório Becta 2005 e 2006, cinco indicadores-chave de e-maturity são necessários para analisar as tendências ao longo do tempo, que são: acesso do estudante às novas tecnologias; qualificação e formação dos profissionais; $E$ learning recursos; Gestão e Estratégia; utilização das TIC em todo o currículo.

Daí a relevância deste estudo que eleva o tema para o universo da Gestão do Conhecimento-GC, afinal, para verificar se uma organização está no caminho certo, na busca efetiva dos melhores resultados, é necessário um mapeamento e um diagnóstico de seu nível de maturidade. A escola é um organismo naturalmente vivo e dinâmico em que todos os seus stakeholders (interessados) têm de aprender a pensar e organizar a escola diante do novo cenário tecnológico, promovendo um espaço para a reflexão e as atividades criativas. Nesse modelo de escola, "só há espaço para uma opção: criar um ambiente que impulsione o compromisso de seu pessoal com a mudança profunda e que seja capaz de mantê-lo sempre atento para que o aprendizado continue sendo um dos desafios mais importantes" (Vassoler e Urbaneski, 2008, p. 59). Nesse sentido, o papel do gestor é fundamental; dentro da visão sistêmica, ele funciona como alavancador. Segundo Senge (2006, p. 95), “o pensamento sistêmico também mostra que pequenas atitudes bem focalizadas podem produzir melhorias significativas e duradouras, desde que atuem no lugar certo. Os pensadores sistêmicos referem-se a esse princípio como 'alavancagem"' e têm como pilar a concepção de construir uma organização que aprende.

[...] organizações nas quais as pessoas expandem continuamente sua capacidade de criar os resultados que realmente desejam, onde se estimulam padrões de pensamentos novos e abrangentes, a aspiração coletiva ganha liberdade e onde as pessoas aprendem continuamente a aprender juntas (Vassoler e Urbaneski, 2008, p.59).

O relatório Becta (2006) afirma que as escolas que fizeram progresso no uso da tecnologia para apoiar a aprendizagem são aquelas onde há forte visão e liderança da gestão e tempo de gestão para planejar e definir metas. Outro aspecto importante considerado é a formação eficiente e eficaz para uso das TICs e a criação das redes de apoio entre pares. Há evidências de que o uso das TICs na educação tem um impacto positivo nos exames nacionais, como apresentou a avaliação Test Bed, por exemplo, o qual indica existir uma associação entre a implantação-uso da tecnologia e a melhoria no desempenho do teste em relação aos indicadores de referência.

É inerente à escola a necessidade de desenvolver habilidades e capacidades para maximizar as oportunidades apresentadas pela tecnologia. Porém, é importante ressaltar que a tecnologia, por si só, não transforma a educação tradicional em uma educação diferente, pois sabe-se que introduzir a tecnologia na comunidade escolar não é suficiente para gerar transformações. Num analogismo a esse princípio lembra-se do trecho da música de Oswaldo Montenegro: "o pescador que se encanta mais com a rede que com o mar".

A grande contribuição é mostrar na prática que a introdução de tecnologia só contribuirá decisivamente para a melhoria da qualidade da educação se os fins e os meios forem reconcebidos. É necessária e urgente uma reengenharia na escola. Portanto, é necessário que a escola estabeleça seus objetivos e renove a organização curricular, os métodos de trabalho, a visão do papel de professores e alunos, as parcerias e a forma de gestão; que dentro de toda essa renovação, faça-se uso criativo e inovador da tecnologia. "Technological innovations are rarely a direct cause of change, but rather they act as a facilitator or amplifier of existing educational practice" (Underwood e Dillon, 2004). 
Segundo Hessel e Abar, "parece que a escola continua alheia aos novos recursos, tal como, no passado, esteve distante da TV, dos instrumentais audiovisuais, das calculadoras etc., apesar da crescente invasão tecnológica em todos os setores da vida social e cultural" (2007, p. 69).

Diversos estudos apontam para o fato de não ser suficiente equipar as escolas, é essencial associar o uso da tecnologia às metodologias fundamentadas em concepções pedagógicas que estimulem a aprendizagem ativa; consequentemente, necessita-se de uma gestão que avance em práticas que promovam uma otimização e potencialização do uso da tecnologia para melhoria dos resultados educacionais. Desta forma, os organismos educacionais precisam consolidar ações e estratégias que colaborem para evolução conjunta da tríade pedagogia, tecnologia e gestão.

\section{Considerações finais}

Esse estudo desemboca na vontade de colaborar na transformação da prática educativa, fomentando inicialmente uma reflexão, muito embora se saiba que a reflexão é extremamente subjetiva, porém "os obstáculos para a mudança estão tanto no campo subjetivo como no objetivo" (Vasconcelos, 2010, p. 11). Ainda que a reflexão não possa interferir objetivamente na realidade, os sujeitos podem atuar através de instrumentos.

Este artigo buscou através de uma abordagem teórica compreender e conceituar o termo e-maturity, pela necessidade de consolidar o termo bastante utilizado na pesquisa de doutorado intitulada E-maturity: gestão da tecnologia em função da melhoria do desempenho educacional, desenvolvida no Programa de Pós-Graduação em Informática na Educação (PPGIE), da Universidade Federal do Rio Grande do SulUFRGS.

Para fundamentar a ideia de maturidade eletrônica, retomou-se a Teoria da Maturidade-imaturidade, de Chris Argyris, que imprime a ideia de que as práticas administrativas podem impedir o amadurecimento e que isto se torna explícito na natureza da organização formal.

Buscou-se, ainda, na Engenharia de software, o Modelo de Maturidade de Capacidade de Software- CMM para compreender a necessidade da evolução das práticas imaturas de gerenciamento em direção a práticas mais sólidas, relacionando-as aos níveis de maturidade.

A partir do estudo, define-se e-maturity como a capacidade e potencialidade da organização escolar de tomar decisões estratégicas e de utilizar de forma eficaz a tecnologia para melhorar os resultados educacionais.

\section{Notas}

\footnotetext{
${ }^{1}$ Fonte dos dados: http://www.oecd.org

2 Tradução: Programa Internacional de Aferição de Estudantes.

${ }^{3}$ Fonte dos dados: Estudos de Benchmarking - Fileira da inovação.

${ }^{4}$ Acessório para o videogame Xbox $360 ®$, onde o objetivo do produto é fazer com que o jogador seja capaz de controlar os jogos com o próprio corpo (Sena, 2011, p. 41).

${ }^{5}$ Site da web de hospedagem e partilha de imagens fotográficas.

${ }^{6}$ Espécie de diário pessoal eletrônico; alternativa popular para a publicação de textos online, uma vez que dispensa o conhecimento mais aprofundado em computação (Baltazar e Aguaded, 2005).

${ }^{7}$ Redes sociais

${ }^{8}$ Papert (1985) chamou de construcionista sua proposta de utilização do computador, considerado uma ferramenta para a construção do conhecimento e para o desenvolvimento do aluno.

${ }^{9}$ Tradução do autor: "Inovações tecnológicas raramente são a causa direta da mudança, mas elas agem como facilitadoras ou amplificadoras de práticas educativas atuais".
} 


\section{Referencias}

ARGYRIS, C. A atitude da direção e seu impacto sobre os empregados. In Personalidade e organização: o conflito entre o sistema e o indivíduo (pp.121-157). Rio de Janeiro: Renes, 1969.

Rio de Janeiro: Renes, 1968.

Personalidade e organização: o conflito entre o sistema e o indivíduo.

BALTAZAR, N.; AGUADED, I. Weblogs como recurso tecnológico numa nova educação. Revista de Recensões de Comunicação e Cultura, 2005. Disponível em: <http://bocc.ubi.pt/pag/baltazar-neusaaguaded-ignacio-weblogs-educacao.pdf >

BECTA. The Becta Review 2005. Coventry: Becta ICT Research, 2005.

Measuring e-maturity amongst work-based learning. Coventry: Becta ICT

Research, 2008.

The Becta Review 2006. Evidence on the progress of ICT in education.

Coventry: Becta ICT Research, 2006.

CHAVES, Eduardo O. C. A educação e tecnologia na sociedade. Disponível em $<$ http://escola2000.net/eduardo/palestras/Florianopolis_arquivos/frame.htm. Acesso em 26/10/2010>.

Educação, Mudanças e Inovação. 2010. Disponível em: <http://www.educacaoetecnologia.org.br/?page_id=121>. Acesso em 26/10/2010

BRUNO, G. Diniz. Maturidade em gestão do conhecimento: um estudo sobre as empresas do setor elétrico. Dissertação de mestrado profissional em administração. Rio de Janeiro: IBMEC, 2008.

FERREIRA, Aurélio Buarque de Holanda. Novo dicionário eletrônico Aurélio da língua portuguesa. Software. Versão 05. Curitiba: Positivo Informática Ltda, 2004.

HUMPHREY, W.S. Characterizing the Software Process: A Maturity Framework. CMU/SEI-87-TR 11, ADA 182895, 1997.

KLERING, Luis Roque. Relação entre estágios de informatização e padrões de comportamento administrativo em organizações brasileiras. Rio Grande do Sul. Porto Alegre: Faculdade de Ciências Econômicas/UFRGS, 1994. 398p. Tese de doutorado.

LIBÂNEO, José Carlos. Adeus Professor, Adeus Professora? Novas exigências educacionais e profissão docente. Ed. Cortez, série Questões da nossa época, vol. 67, 2000. 104 p.

OCDE. Disponível em: <http://www.oecd.org>. Acesso em: 10 de dezembro de 2010.

MARTINEZ, Maria Carme e PARAGUAY Ana Isabel Bruzzi Bezerra. Satisfação e saúde no trabalho: aspectos conceituais e metodológicos. Cadernos de Psicologia Social do Trabalho, 2003, vol. 6, pp. 59-78.

MONTENEGRO, Oswaldo. Metade de mim. Música, [199_].

NAKAIAMA, Marina Keiko. A influência da cultura organizacional na predisposição do gerente ao estresse ocupacional. Rio Grande do Sul. Porto Alegre: programa de pós-graduação em administração/UFRGS, 1997.168p. Tese de doutorado.

NEHME, Marcelo Carlotto. Reestruturação organizacional: reflexos nas lideranças intermediárias. Rio Grande do Sul. Porto Alegre: programa de pós-graduação em administração/UFRGS, 1998, p. 42. Dissertação de mestrado.

PAPERT, S. A máquina das crianças: repensando a escola na era da informática. Porto Alegre, Artes Médicas, 1994. Logo: computadores e educação. São Paulo, Brasiliense, 1985. 
PMI, Project Management Institutute (2004) A guide to the Project Management Body Knowledge (PMBok) 3rd edition. Project Manegement Institute. Inc.

RAUEN, Cristiane Vianna e HIRATUKA, Célio. A universalização dos serviços de telecomunicação: comparações entre Brasil e países da OCDE. Ensaios FEE, Porto Alegre, v. 31, n. 2, p. 503-534, dez. 2010.

SENGE, Peter M. A quinta disciplina. 21 a Edição - Rio de Janeiro: BestSeller, 2006. UNDERWOOD, J.; DILlON, G., Capturing Complexity through maturity Modelling. Technology, Pedagogy and Education, Vol. 13, No. 2, 2004, 213-225.

VASSOLER, Márcia Cecilia e URBANESKI, Vilmar. As cinco disciplinas de Peter Senge e a escola que aprende. Revista de divulgação técnico-científica do ICPG. Vol. $3 \mathrm{n}^{\mathrm{o}} 12$ - jan.-jun./2008.

VASCONCELOS, Celso dos S. Planejamento: projeto de ensino aprendizagem e projeto político pedagógico - elementos metodológicos para elaboração e realização. $21^{\mathrm{a}}$. Edição. São Paulo: Libertad, 2010. 